\title{
THE CONTRIBUTION OF GESTURES TO PERSONAL BRANDING
}

\author{
Brînduşa-Mariana Amălăncei \\ "Vasile Alecsandri" University of Bacău \\ brandusa_amalancei@yahoo.com
}

\begin{abstract}
A form of (self-)promotion but also an authentic strategic choice, the personal brand has become a topical preoccupation of marketing specialists. Personal branding or self-marketing represents an innovative concept that associates the efficiency of personal development with the effectiveness of communication and marketing techniques adapted to the individual and that comprises the entire collection of techniques allowing the identification and promotion of the self/individual. The main objective is a clear communication with regard to personal identity, no matter by means of which method, so that it gives uniqueness and offers a competitive advantage. Although online promotion is increasingly gaining ground for the creation of a personal brand, an individual's verbal and nonverbal behaviour represent very important differentiating elements. Starting from the premise that gestures often complement, anticipate, substitute or contradict the verbal, we will endeavour to highlight a number of significations that can be attributed to the various body movements and that can successfully contribute to the creation of a powerful personal brand.
\end{abstract}

\section{Keywords}

brand; (self-)promotion; identity; gestures; nonverbal communication

\section{JEL Classification}

M37

\section{Introduction}

The term personal brand refers to a clear, powerful and persuasive public image with regard to a person (Montoya \& Vandehey, 2009), reflecting the personality, qualities, values and experience that confer uniqueness upon an individual and differentiates him from the others. It is considered that anyone can be a powerful brand, which does not entail the change of one's personality and does not represent an attempt to be one thing or another. A powerful personal brand uses the intrinsic special qualities of a person in order to make a difference, thus distinguishing itself from a product brand, which is constructed on the basis of the extrinsic characteristics attributed to the product by the others (Mcnally \& Speak, 2002). A personal brand represents a promise made to the ones we interact with, thus creating certain expectations in their minds. By means of a personal brand, which is considered a form of (self-)promotion and even selfishness (Montoya \& Vandehey, 2009), as well as an authentic strategic choice, thus adding extra personal value.

The process by means of which persons or entrepreneurs try to differentiate themselves, highlighting their unique value both personally and professionally, bears the name of personal branding (Schawbel, 2010). In effect, personal branding does not refer to the creation of an image for the external world, but to the discovery and maximization of one's strong points and to the understanding of the unique combination between rational and emotional resources and their employment with the purpose of differentiating oneself from the others (Nedelea, 2009). It is believed that 
branding will become the strongest weapon in the public space, thus being able to influence, positively or negatively, any decision at any level (political, cultural, social, or even military). A suggestive example for that matter is represented by the Obama brand - a charismatic brand with high rates of success, as demonstrated both by the number of those who, putting all their hopes in him, voted for him, and by those who have identified themselves with him and the American dream and have been the voice of all Afro-Americans since the beginnings of the USA until the present (Cărămidă, 2009). In the world of fashion, there are numerous brands that bear the name of their founders (Armani, Christian Dior, Chanel etc.) and that present certain attributes, offer a series of advantages and transmit clear values, which represent a given conception, just as in the world of business Donald Trump is associated with the idea of force, power, aggressiveness, but also with that of keeping promises (Bădulescu, 2012).

Although it is believed that social media represents a manner of promotion that is a lot more efficient than offline promotion in the construction of a personal brand, the personalization of the way of talking, making gestures, dressing, adopting an attitude or displaying qualities has a very important contribution. Everything that is transmitted verbally is in fact enhanced or deviated by means of gestures, understood as movements of the body or body parts with the clear intention of influencing the receiver. Thus, in our paper we intend to highlight the significant contribution of gestures to the image the others create about the speaker.

\section{Gestures and their communicative action}

Even as far back as the antiquity it was believed that, as it happens in the case of voice, "gestures conform to the intellect" and "express, without words, almost everything” (Quintilian, 1974). However, besides the significance they have in discourse, gestures offer supplementary information regarding the personality and feelings of the communicator, constituting, in their own right, a language about the intentions of the person that talks. Even more, in each of us there are, unconsciously, rules that create an effective grammar of gestures (Chétochine, 2010).

Gestures are involved in the communicative action, materialized in "language" games, where verbal and extra-verbal means of expression are formed and interconnected by means of completion and substitution rules. The consensus implied in the action that contains the language game refers both to the propositional contents of the expressions/constructions (opinions) and to the expectations of reciprocal behavior (norms), intersubjectively valid, to which we answer together with our expressions (Habermas, 1983). Therefore, two important roles of gestures result from here, in relation with the verbal - that of complementing and that of substitution -, as well as the intentional character that defines them.

The concept of game has a central role in the work of one of the predecessors of the theory of communicative action, namely, George Herbert Mead. Mead talks about a conversation of gestures and considers that the game intervenes in the understanding of the gesture as a significant symbol, in the passage or transfer from the Self to the Generalized Other and in social communication. In other words, along with the gesture a symbol is transmitted, and the person one interacts with could not answer if he/she were not capable of decoding the meaning of the symbol expressed by that gesture. In order that dialogue may become possible, both sender and receiver must attribute the same meaning to the gesture. Thus, people signal to themselves the meanings of their own gestures which, on condition that they are the same for all those involved in the interaction, enable gestures/ symbols to be significant: "Gestures become significant symbols when the person who is making them expects to elicit 
from the one to whom the gestures are addressed the same kind of response he/she would have given if he/she had been in the interlocutor's place” (Mead, 1934; 2006). Therefore, the body parts contribute, along with the mind, to the communication of pure intellectual ideas; more precisely, the somatic actants signal, highlight one thing or another, or model and control the objects that surround us. Like words, gestures also produce a certain kind of reverberation in interaction, a resonance that goes beyond the simple correspondence with the indicated entity, thus giving rise to the idea that a halo/an aura accompanies certain gestures and thus the notion of connotation emerged as a series of "insensible emotional and subjective factors that accompany denotation". Consequently, a gesture acquires meaning only in combination with other signs, the gestural syntagms (gestures taken separately) being partial expressions whose weakening of semantic value occurs when they are integrated in larger syntagms. The gestural syntagm arises either as a meaningless syllable or as a word, and the meaning can arise or disappear during the observation, a reason that made the American semioticians deal not with the practical behaviour but with the significant one, which is opposed to the practical one (Şoitu, 1997). Given that a gesture cannot be divided into syntagms with their own signification and that signification is born in our presence as receiving spectators, we can observe that the problem of meaning/signification becomes even harder to solve.

The movements of various body parts can create significant gestures that lie at the basis of the image the others make concerning the feelings, attitudes or experiences of the speaker. However, in case of the many attempts to catalogue these gestures in specialized books on nonverbal communication the signification attached to them often seems purely speculative in nature. Nevertheless, an important contribution in this respect can be found in the oratory of the antiquity, and among those who dealt with the role of body parts for the construction of significant gestures in the act of uttering a discourse we can identify Marcus Fabius Quintilian.

One of the most expressive body parts is the head. It contributes to the beauty of discourse when its position is upright and natural, whereas a head bent forwards shows humbleness, one moved backwards suggests arrogance, bent sideways it shows idleness, while its stiff and unbending position can show strength of character (Quintilian, 1974: 297). Seven categories of gestures involving the head have been identified, as follows: 1) the movement of the head forwards (expressing interest in the interlocutor's speech); 2) an inclined head (shows submission, lack of will and hope; inclining one's head in greeting shows politeness; keeping one's head in an inclined position for a longer time may reveal the feeling of shame); 3) nodding (the movement of the head downward repeatedly is perceived as a sign of assent, agreement and understanding related to what the interlocutor says; accompanied by raising one's eyebrows and half-opening the mouth, nodding signals great interest in what is transmitted); 4) the raising of the head (indicates self-confidence, awareness of one's value, pride, the ability to act; the stiff raising of the head expresses vanity and arrogance); 5) the movement of the head backwards and upwards (suggests relaxation, daydreaming, the desire to get away from it all); 6) the movement of the head toward one side (toward the right - it indicates affinity, lack of will, resignation; toward the left - it signals skepticism, a critical attitude, or requesting supplementary information); 7) the swaying of the head (expresses both agreement and disagreement, lack of certainty or inclination to compromise; if accompanied by the raising of the shoulders and drooped mouth corners it indicates indecision and disappointment in certain situations; Rückle, 1979; 1999). Therefore, the head mirrors the spiritual condition in many ways and besides the movements indicating approval, refusal, or confirmation other movements are also known and common, such as those that signal shame, doubt, admiration, or indignation. However, it is erroneous to resort only to 
gestures with the head, to frequently move the head, to agitate the head or to turn it in all directions (Quintilian, 1974).

Physiognomy also has an essential role in communication. With the help of our countenance we implore, threaten, flatter, we display signs of joy, pride, or humbleness. At the level of our physiognomy, the greatest impact is that of the eyes, whose movements can express, depending on the situation, determination, indifference, pride, warning, kindness or severity. A speaker that keeps his/her eyes completely or slightly closed denotes lack of experience or intelligence. The eyes transmit these feelings with the help of the eyelids, cheeks and eyebrows. The eyebrows "dominate the forehead; they contract it, broaden it or make it smaller". It is unadvisable to keep one's eyebrows completely unmoving, too mobile, unequally moved or in disagreement with the words uttered. By contracting our eyebrows anger is transmitted, whereas by lowering them we suggest sadness; by relaxing them we express joyfulness as well as approval and by raising them we indicate interdiction (Quintilian, 1974). An experimental study based on the analysis of the photographs of men belonging to different races revealed that through the different positions of eyebrows ("lowered" or "raised") information is transmitted regarding the dominating/ dominated status of the interlocutors (Keating, Mazur \& Segall, 1977). At the same time, given our habitual observation it seems that the lifting of the eyebrows while listening to the other's speech is a sign of surprise, whereas their lowering transmits distrust in what is said.

As far as the gestures involving the hands are concerned, Marcus Fabius Quintilian argues that they are ,the language common to all people”, thus being able to constitute, as in the case of words, a language in itself. With the help of hands, we express a request, a promise, a calling, a threat, or interrogation, negation, dread, fear, joy, sadness, doubt, regret, confession, admiration, shyness, measure, quantity, number, or time. Such gestures accompany words naturally, but there are also gestures that are meant to imitate, by means of which we transmit the equivalent idea and which are not recommended to be used during discursive interventions (Quintilian, 1974).

The author quoted above mentions that a very common gesture results from the placing of the middle finger on the thumb and the stretching out of the other three fingers. It is believed that when the hand is held out and slightly moved towards the right and the left, discreetly accompanied by the head and the shoulders, this gesture shows certainty. The holding out of the index finger is a very useful gesture when we want to criticize or point at something. When the hand is raised and moved towards the shoulder slightly inclining the finger, it is an indication of affirmation, whereas when the finger is directed towards the ground, somewhat reversing it, we signal insistence. The gesture of drawing together the tips of the first four fingers, holding up the hand towards the mouth and turning it downwards while slightly stretching it corresponds to a modest way of being. The words seem to be "drawn" towards the interlocutor when the speaker pulls the hand toward himself with the fingers turned downward, with a somewhat easy gesture, then opens it more widely and stretches it out to the contrary direction. A gesture that is common to informal and somewhat shy communication is that of slowly opening the hand, as if in a promise, and of moving it along short distances, while the shoulders follow it discreetly. In order to express admiration, the hand is slightly turned towards the sky, then the fingers are curled up in turn, starting with the little finger and then, by means of the reverse movement, the hand is opened and turned in the opposite direction. Normally, when we ask, we turn our hand towards the one to whom our question is addressed, by means of a smooth hand gesture we promise and express consent, whereas by means of a more vivid gesture we encourage and sometimes praise. By lifting the tip of our fingers drawn together toward our mouth we express weak surprise, sometimes sudden indignation, 
the feeling of fear or a prayer, whereas regret or anger are expressed by clenching our fist and lifting it to the chest. For great orators it is a mistake to raise one's hand higher than the level of the eyes or above the head, to move it down lower than the chest or to put it on the lower abdomen, as well to gesticulate only with one's left hand (Quintilian, 1974).

Certain authors who focused on nonverbal communication highlighted the significance of the gestures in which the hands are involved, dividing them into gestures made with the fingers, with the palms, with the fists and with the arms (Chelcea, Ivan \& Chelcea, 2005). Thus, the use of the index finger when gesticulating has diverse significations. Even though the code of good manners interdicts the gesture of pointing with the finger, it seems that for the Americans this prohibition is not valid, with many politicians on the stage or on the stairs of the presidential helicopter using this gesture strategically in order to indicate a person from the public whom they notice with surprise and to whom they smile.

Pointing the index finger at a person has the role of "wand" and indicates the dominating position of the one using it. With the help of the index finger, moving our hand up and down, we scold, whereas extending it accompanied by a closed fist and the swaying of the hand from left to right indicates our refusal or disagreement. Together with the thumb as well as with the middle finger, the index forms emblems (for instance, in the former case, it substitutes the term "OK", and in the latter situation, it takes the form of letter V so as to signify "victory"). It seems that the index finger is the most expressive of our fingers, both in gestures of touching one's own check or temple and in gestures that synchronize it with the other index finger. In America, finger counting starts with raising the index finger first, then the middle finger, and so on, whereas in Europe the thumb is first held up, then the index finger and the middle finger. Hand rubbing is a sign of positive evaluation related to what is about to come, but the meaning of this gesture largely depends on the quickness of the movement and the real social situation. Putting both palms together with fingers crossed transmits a negative attitude - the higher the hands are raised, the more intense it is. Finally, holding hands like an upturned V (resembling the form of a helmet) convey self-confidence, especially in the case of persons with a superior social position.

As far as the gestures involving the movement of the trunk are concerned, it is believed that bending the torso forwards signifies closeness, interest, aggression, planning an activity, whereas moving it backwards can indicate retreat, lack of interest (preoccupation for one's own thoughts), haste, or the lack of planning regarding an activity connected with the partner (Rückle, 1979). When trying to decode the nonverbal messages transmitted by means of gestures resulting from trunk movements, the analysis of distances and posture offers useful information.

Considered a "transfixed/frozen gesture" that differs from the position of the body (Chelcea, Ivan \& Chelcea, 2005), posture acquired the following significations in William James's view (1932), on the basis of experimental results: the attitude of closeness, a situation in which the body is bent forward, as a sign of giving attention; the attitude of rejection, by means of which we avoid the other, signaling refusal or repulsion; the attitude of expansion, a case in which the head, trunk and shoulders are extended, with the suggestion of arrogance, pride, aggressiveness; the attitude of contraction, with an inclined head and drooping shoulders, suggests disappointment and depression (cf. Corraze, 1980; 2011). An important element of nonverbal communication is represented by the relation between the posture and the degree of intimacy, any transgression of the intimate space by means of the posture leading to psychic discomfort. 


\section{Conclusions}

We can conclude that, together with the markers of position or rank, or those of clothing, age, gender, race, body size and physical appearance, body carriage and speech features, gestures, one's facial expression and posture represent behavioral elements with expressive and communicational force, being included in what Erving Goffman calls "face/personal facade" (personal front) - defining one of the elements employed by the individual actor when performing. More precisely, the author claims that, in most routine meetings, individuals tend to present a front/facade. It contributes to defining the situation for those who are watching the "scene". In its turn, the scene includes, on the one hand, the scenery (settings), which is made up fixed elements furniture, scenic decoration, background objects etc. - whose variations influence the behavior of all those involved in the situation given and, on the other hand, the personal front.

Depending on the function performed by the information they convey, the stimuli composing the personal front are divided into "outward aspect/bearing” (appearance) and "attitude" (manner). The "outward aspect/bearing" refers to those stimuli that offer information regarding the social status of the individual and their temporary ritual state (if they are engaged in a formal social activity, in some professional occupation or if they are enjoying a moment of relaxation). The "attitude" involves those stimuli that, at a certain moment, can warn about the interactive role the performer expects to play/act in a situation that is about to take place: "Therefore, a proud, aggressive attitude can give the impression that the performer expects to be the initiator of the verbal interaction and the one directing its course. A shy, justificatory attitude can give the impression that the performer expects to follow the ones that take control or that at least he can be determined to do so" (Goffman, 1959; 2007).

The individual appears to be an ,actor in action” that, unlike the social actor, is a real self that is confronted with real and unpredictable situations, which determine him to continuously reinvent his own roles. By means of this interactive show/performance, he induces certain impressions about himself, and these impressions translate his personal demeanour and influence the others in understanding the events they are taking part in.

Gestures are, therefore, more than complementary elements; they contribute to enhancing messages and impressions. Researchers identified "series of frequency" in which gestures amplify the linguistic expression. Thus, the smile of a person that is talking is frequently associated with an insistent look, whereas the smile of a person that is listening is often accompanied by a gesture of approval. When the flow of speech is slow, the gestures are quicker than the verbal flow and consist of head movements. If the pitch of the voice is heightened or deepened at the end of a sentence, the corresponding gestures are those of raising or lowering the eyelids, the head and/or the hands. Gestural amplitude correlates with the dimension of the uttered linguistic unit, the sentence segments often being accompanied by short and varied gestures made by the most mobile body parts, whereas ample verbal units are associated with large gestures or even with changes in posture. Finally, gestures and verbal utterances harmonise at the level of contents (for instance, a pointing gesture is almost always attended by a verbal deictic element). It has also been observed that gestures anticipate verbal expression (for example, by turning towards the interlocutor and by means of specific gestures such as searching for the partner's look, a smiling or angry facial expression depending on the communicating intention etc., we "prepare" corporally in order to start talking) and supply important information concerning the identity of the social actors (personality, social background, health condition), their emotional state or the relations they have with others. Consequently, we can state that the gestural language has a significant role both in the case of personal branding and the facilitation of social interaction and its functioning. 


\section{References}

Bădulescu, T. (2012), Introducere în branding-ul personal, available at http://www.traianbadulescu.ro/2012/10/18/introducere-in-branding-ulpersonal/.

Cărămidă, C. (2009), Brand\&Branding. Visual Identity, I, Bucureşti, Brandmark.

Chelcea, S., Ivan, L., Chelcea, A. (2005), Comunicarea nonverbală: gesturile şi postura, Bucureşti, Comunicare.ro.

Chétochine, G. (2008), La vérité sur les gestes, Paris, Eyrolles.

Corraze, J. (2011), Les communications non-verbales, 6 e édition, Paris, PUF.

Habermas, J. (1983), Cunoaştere şi comunicare, Bucureşti, Editura Politică.

Goffman, E. (2007), Viaţa cotidiană ca spectacol, Bucureşti, Comunicare.ro.

Keating, C. F., Mayur, A., Segall, M. H. (1977), Facial gestures which influence the perception of status, Sociometry, 40(4), 374-378, available at http://www.jstor.org/discover/10.2307/3033487?sid=21105542171081\&uid=7 0\&uid=2129\&uid=4\&uid=3738920\&uid=2.

McNally, D., Speak D. K. (2002), Be Your Own Brand - A breakthrought formula for Standing Out of the Crowd, San Francisco, California, Berrett-Koehler Publishers.

Montoya, P., Vandehey, T. (2009), The brand called you, United States of America, The McGraw-Hill Companies.

Mead, G. H. (2006), L'esprit, le soi et la société, Paris, PUF.

Nedelea, A. (2009), Bazele marketingului, Iaşi, Sedcom Libris.

Quintilian, M. F. (1974), Arta oratorică, III, Bucureşti, Minerva.

Rückle, H. H. (1999), Limbajul corpului pentru manageri, Bucureşti, Editura Tehnică.

Schawbel, D. (2010), 4 steps to building your future, New York, Kaplan Publishing.

Şoitu, L. (1997), Comunicare şi acţiune, Iaşi, Institutul European. 